\title{
Open For Learning: The CMS and the Open Learning Network
}

\author{
Jon Mott and David Wiley \\ Brigham Young University
}

\begin{abstract}
The course management system (CMS) reinforces the status quo and hinders substantial teaching and learning innovation in higher education. It does so by imposing artificial time limits on learner access to course content and other learners, privileging the role of the instructor at the expense of the learner, and limiting the power of the network effect in the learning process. The open learning network (OLN) — a hybrid of the CMS and the personal learning environment (PLE) - is proposed as an alternative learning technology environment with the potential to leverage the affordances of the Web to improve learning dramatically.
\end{abstract}

Keywords: course management system; higher education; open learning network; personal learning environment; technology; Internet 


\section{Open For Learning: The CMS and the Open Learning Network}

Twenty-five years ago, Bloom and his colleagues demonstrated that the average student is capable of performing at a radically higher academic level than s/he generally does (Bloom, 1984). Through a series of comparative studies--in which students of different age groups studied different subject matters under different instructional conditions--Bloom established that the average student instructed individually by a tutor outperformed $98 \%$ of students instructed in a conventional classroom setting. It was a critical statement about formal education in both senses of the term. First, it was a critique: the average student is capable of learning significantly more than s/he does, but formal education does not consistently facilitate the realization of that potential. Second, it highlighted an extremely important opportunity - educational researchers need to engage in work focused on decreasing the delta between student potential and achievement. Bloom (1984) summarizes:

I believe an important task of research and instruction is to seek ways of accomplishing this [academic success] under more practical and realistic conditions than the one-to-one tutoring, which is too costly for most societies to bear on a large scale. This is the "2 sigma" problem. Can researchers and teachers devise teachinglearning conditions that will enable the majority of students under group instruction to attain levels of achievement that can at present be reached only under good tutoring conditions?.... If the research on the 2 sigma problem yields practiced methods (methods that the average teacher or school faculty can learn in a brief period of time and use with little more cost or time than conventional instruction), it would be an educational contribution of the greatest magnitude. (p. 4-5, emphasis added)

Bloom, along with a host of other educational researchers and reformers, has long believed that technologically driven instructional methods have the potential to help bridge the 2-Sigma gap. However, such high hopes for technology's impact on learning outcomes have been largely unrealized. Bush and Mott (2009) have argued that the failure of technology to transform learning stems from a preoccupation with "the tactical implementation of specific technologies which often simply automate the past" (p. 17). Despite billions of dollars (see Nagel 2008), and millions of person-hours invested over the past two decades, recent instructional technology practice in higher education has largely been a perpetuation of this trend.

In the mid-1990s, largely unaware of Bloom's challenge, innovative faculty members and students at universities throughout the world began thinking about ways to leverage the Internet and the World Wide Web to improve teaching and learning. The result was the creation of a new category of web-based software: the "course management system" or CMS. Alternatively labeled learning management systems (LMSs), learning content management systems (LCMSs), and virtual learning environments (VLEs), such software has generally been focused primarily on helping teachers increase the efficiency of the administrative tasks of instruction (e.g., distribute documents, make assignments, give quizzes, initiate discussion boards, assign students to working groups, etc.). This instructor-centrism comes despite the best intentions and efforts of system designers, early adopters, and instructional support staff who sought to use these systems to transform the dominant learning modality of higher education from traditional, classroombased instruction to online and hybrid courses. In practice, the vast majority of instructors who adopted the CMS largely ignored Bloom's challenge to make an "educational contribution of the greatest magnitude," instead focusing on increasing the administrative efficiency of their jobs. 
Evidence to support this claim comes from several quarters. First, 5 years of data on faculty feature usage in Blackboard (the leading commercial CMS) at Brigham Young University evidences the tendency to use the CMS to improve instructional efficiency rather than effectiveness. When asked what features of Blackboard they use in their courses, more than twothirds of faculty members $(n=813)$ at BYU report using the teaching administration tools in Blackboard while less than a third report using the more learning focused tools (see Table 1).

\section{Table 1}

Self-Reported Function Usage in Blackboard by BYU Faculty Members (2004-2009)

\begin{tabular}{|l|l|}
\hline Feature & Percentage of Faculty \\
\hline Course Materials / Documents & $85.9 \%$ \\
\hline Gradebook & $78.8 \%$ \\
\hline Announcements & $68.5 \%$ \\
\hline E-mail & $67.4 \%$ \\
\hline Assessments / Quizzes & $33.7 \%$ \\
\hline Discussion Boards & $15.0 \%$ \\
\hline Virtual Classroom & $1.2 \%$ \\
\hline
\end{tabular}

These patterns of CMS usage at BYU are consistent with the findings of a 2003 study of University of Wisconsin System faculty members. In that study, Morgan (2003) found that "faculty use the CMS primarily as an administrative tool to facilitate quiz administration and other classroom tasks rather than as a tool anchored in pedagogy or cognitive science models" (p. 11). As Milligan (2006) observes, the CMS are "fundamentally a conservative technology ... [for] managing groups, providing tools, and delivering content" (p. 1). Evidence of the pervasiveness of such CMS usage tendencies can be found in a recent usage study of the Sakai at the University of North Carolina. Faculty survey data indicates that the top three uses of Sakai in the category "Improving Teaching and Learning" were "Accessing materials any time," "Saving me time," and "Managing my course activities" (UNC 2009, p. 15).

While many proponents of the CMS hoped that it would yield dramatic improvements in learning, the reality is that it is primarily used as an administrative toolbox. Consequently, we have yet to leverage the potential of the Web to yield the kinds of dramatic improvements that Bloom envisioned. Based on the usage data above, one possible characterization of the CMS is a very effective, albeit very expensive, course content distribution and teacher-student communication platform. While improvements in efficiency are certainly beneficial to faculty members and students, the CMS has yet to yield consistently demonstrable, replicable, significant improvements in learning outcomes. Using Web technology primarily for the purposes of content distribution and secure communication between faculty and students in higher education is akin to using a desktop computer for a doorstop. A desktop can certainly work well for that purpose, but it falls far short of its intended use and its full potential. 
That technology has failed to transform learning-the core function of educational institutions - is troubling. After billions of dollars invested, we are left to conclude that educational technology has been "oversold and underused." In his so-titled book, Cuban (2001) details his findings of an exhaustive study of educational technology investments in Silicon Valley. His conclusions are not encouraging - he found little evidence that technology has yielded any significant changes in teaching practices (p. 130). On the contrary, Cuban (2001) concluded, "teachers used technology to maintain existing practices" rather than to "revolutionize" the way they teach their students (p. 138).

Herrington, Reeves, and Oliver (2005) tie Cuban's thesis directly to the course management system. They argue that course management software leads universities to "think they are in the information industry" (p. 356). In contrast to "the authentic learning environments prompted by advances in cognitive and constructivist learning theories," the industrial, course management model has its center of gravity in teachers generating content, teachers gathering resources, teachers grouping and sequencing information, and teachers giving the information to students (Herrington, Reeves, \& Oliver, p. 356). This is so, they argue, because teachers "often yield to the seductive appeal of a course management system, where it is easy enough to populate a weekly schedule with static resources and decontextualized tasks," which results in a "focus on content ... rather than the process of educating the student" (Herrington, Reeves, \& Oliver, p. 357). They conclude:

There is much evidence to suggest that universities and other educational institutions have failed to perceive the difference between educating learners and simply providing them with information and content. Most institutions of higher education appear focused on . . . content coverage, course structure, and pre-existing time arrangements such as semesters and hours of credit than . . . issues such as learning and performance. (Herrington, Reeves, \& Oliver, 365)

Notwithstanding the massive allocation of resources to educational technology, course management systems, educational research, and instructional design, the educational establishment's resistance to change at its core is remarkable. The transformational impact of technology can be seen in almost every other aspect or sector of culture, society, and the economy. Indeed, a quick review of several recent books about the dramatic impact of Web technologies in the wider world reveals an odd absence of even passing references to the impact of these technologies on education. The indexes of books such as The Long Tail, Wikinomics, Here Comes Everybody, and Tribes contain zero entries under the topics of "education," "learning," or "school." This is potent confirmation of Western Governors University President Bob Mendenhall's observation that, "Technology has changed the productivity equation of every industry except education" (Webb, 2009).

Accordingly, we assert that the persistence and perpetuation of the CMS paradigm is resulting in a missed opportunity of epic proportions. Instead of leveraging the Web to improve student performance radically and close Bloom's 2-Sigma gap, instructors and institutions are essentially making the old, content-centric paradigm more efficient, but leaving it largely unchallenged and unquestioned.

In this article, we argue that the CMS paradigm, as it has evolved over the past decade, is poorly equipped to close the 2-Sigma gap. As currently designed and implemented, not only does the CMS fail to help learners realize their full potential while engaged in formal learning, but it 
also fails to prepare them to be effective learners throughout their working lives. We contend that the CMS falls short in three important ways. First, the CMS imposes, or at least reinforces, artificial time constraints on learning and learning continuity. It does this by perpetuating the Industrial Era-inspired, assembly line notion that the semester-bound course is the naturally appropriate unit of instruction (Reigeluth, 1999). This student throughput-focused model perpetuates the increasingly false notion that career preparation and learning occur during a discrete, uninterrupted, several-year-long period immediately following high school. Second, while the job marketplace increasingly puts responsibility for learning and authentic, job-related skill acquisition and refinement on the individual, the CMS continues to privilege the instructor as the locus of energy and action in the learning process. The CMS does not afford learners the opportunity to contribute to the learning process in significant ways or to self-organize around learning topics, conversations, or content. Finally, the CMS continues to artificially situate instruction and learning inside walled gardens that are disconnected from the rich and vibrant networks of learners and content in the wider world.

After discussing these three aspects of CMS inadequacy, we propose an alternative teaching and learning infrastructure that is better adapted to the learning demands and career realities faced by our students. However, in doing so, we also note that the changes necessary to bridge the 2-Sigma gap are at least as much cultural and pedagogical as they are technological.

\section{Artificial Time Constraints in the CMS}

Virtually every CMS implemented at colleges and universities throughout the world is integrated with each local institution's student information system (SIS). This integration allows for the automatic creation of "courses" inside the CMS associated with each section in the class schedule in a given semester or term. This is an incredible efficiency affordance for faculty members and students. With a few keystrokes and mouse clicks, every student formally registered in a section is automagically added to the class roster in the CMS. This integration between the CMS and the SIS is one of the most important drivers of CMS adoption in higher education-it is highly unlikely that instructors would use a CMS if they were required to manually construct and update their class rosters throughout the semester.

While SIS integration is a positive, necessary element of any viable online learning environment, the tight coupling of the CMS with the SIS and the class schedule has resulted directly in an unintended consequence of CMS deployment by artificially limiting the potential of the Web to keep students connected to each other and their content. While the CMS facilitates substantial interaction and community building around content within courses, the resulting learning communities are usually limited to those formally enrolled in the course and those communities exist only for the duration of a particular semester or term. When each period of instruction draws to a close, CMS courses are routinely deactivated and sometimes even deleted to make way for the next semester's courses. CMS administration realities (content storage, backup, bandwidth consumption, user account administration, etc.) and licensing restrictions on the number of active users in the CMS further reinforce this tendency.

Because CMS administration is tightly tied to the academic calendar, semesters, and terms, it has become an additional, powerful source of inertial energy behind the course-centric, content-driven model of instruction that dominates higher education. The net result is a procession of successive 14-week starts and stops in a student's educational career at the typical college or university. The initial picture of growth in an individual learner's "network" is 
encouraging, as illustrated in Figure 1 below. Although narrowly limited to the community of enrolled students in a particular section of a course, students have the opportunity to build connections with each other, their instructor, and the content published within the course site in the CMS.

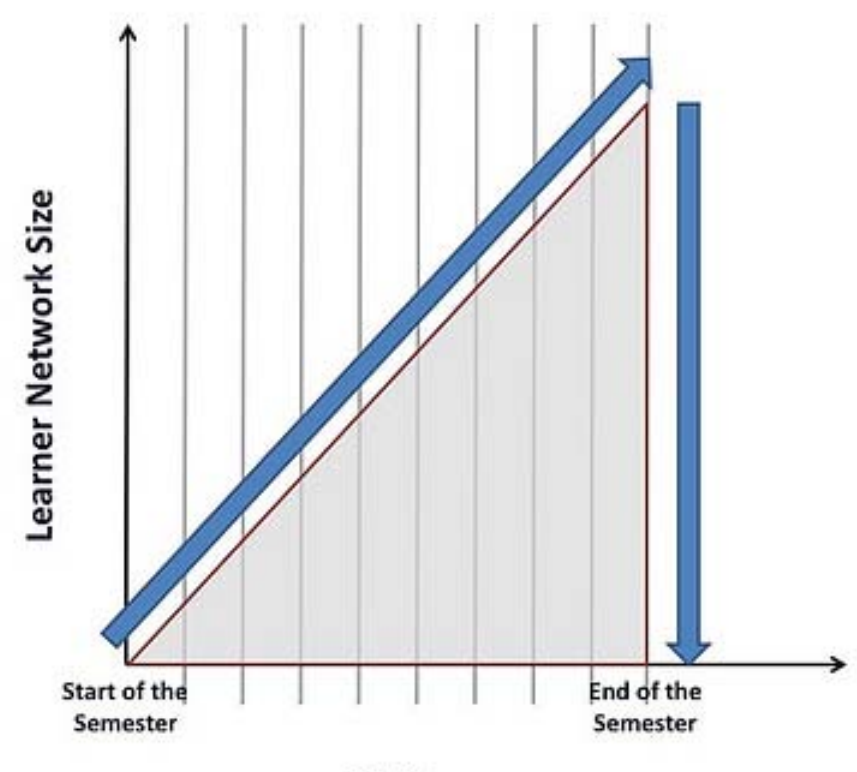

TIME

Figure 1. Growth of the learner network in a CMS.

However, at the end of each semester, courses are routinely "deleted" and the learners' networks are gone, with no record left behind of the activity and learning that occurred within them. This pattern repeats from semester to semester, throughout a student's learning career at a particular institution.

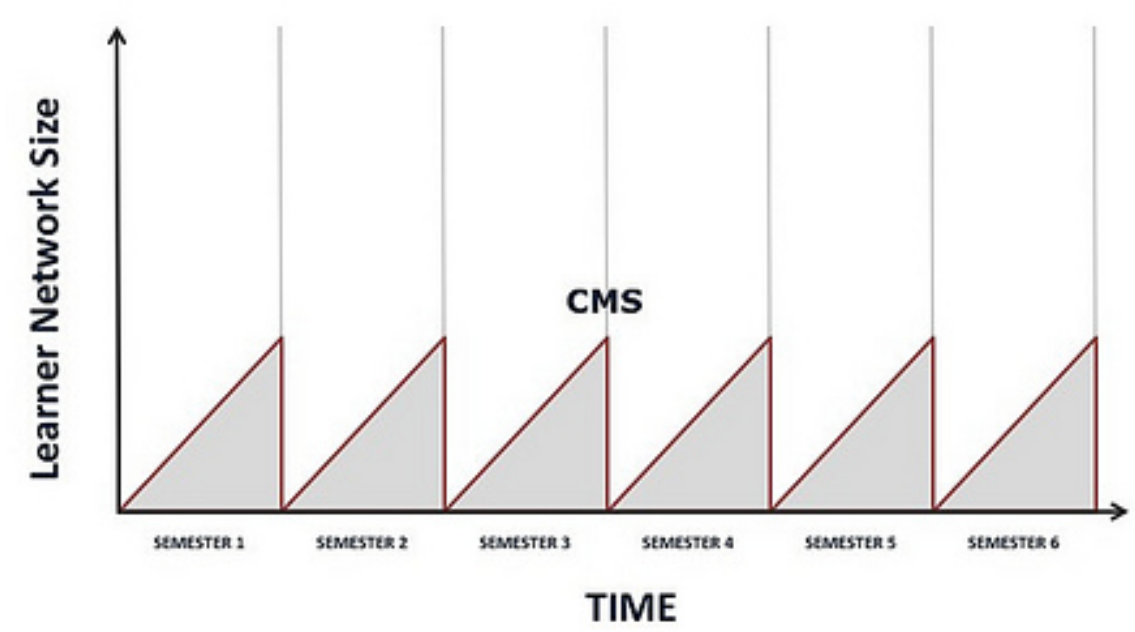

Figure 2. Growth of the learner network in a CMS over time. 
These learning network disruptions are even more jarring for students who transfer from one institution to another or those who take courses from multiple institutions. Unless students fastidiously copy the content from their CMS courses and save the contact information of their classmates, the learning network connections they have made (both content and social) are essentially lost. If Facebook operated in such a manner, deleting users' friends, wall conversations, pictures, and other data every 14 weeks, users would be furious. They would leave Facebook in droves for applications that preserve their networks over time. While students generally do not have formal alternatives to the CMS, indeed, they are flocking to time-persistent social networking and media sharing sites like Facebook, Flickr, YouTube, GMail, and Google Docs.

By scouring the CMS clean of any evidence that students were ever there at the end of every semester, we are denying learners an opportunity to act on what Campbell (n.d.) considers a fundamental human need to leave behind their "cognition prints," some indication that they were there and made a difference. This urge is manifest in a variety of forms, perhaps most powerfully manifest by human propensity to leave their initials behind on trees and park benches or to tag public spaces with graffiti. In an educational context, this plays out as notes in textbooks or less benignly as initials or commentary etched on desks or classrooms walls. While the online learning space provided in the CMS is qualitatively different from the classroom space, students still long to leave behind their mark. This need is increasingly met through discussion boards, social networking sites, blogs, and wikis. Campbell (n.d.) suggests that we and our students naturally gravitate to these outlets because they are observable (see also Rogers' Diffusing Innovations, 1995), they are persistent (they remain behind, virtually forever, for even very small groups of viewers to see), and they create a shared sense of intimacy between the creator, the viewer, and the broader community.

While activities captured within a course site in a CMS can create, within the above noted constraints, a sense of intimacy within a community of learners, those communities do not persist. While we know of no formal research on the topic, we believe that knowing that the fruits of their efforts will be categorically deleted at the end of term is a significant negative motivation for students to contribute meaningfully within the CMS, particularly when the same effort invested elsewhere would persist indefinitely. Even during the time their efforts remain "live" in the CMS, they are not as broadly observable as they would be elsewhere. For these reasons, Campbell declares that CMS courses are "on the web but not of the web."

Maintaining access to content and community is increasingly important to learners, both while enrolled in post-secondary institutions and after they graduate from them. Unfortunately, teachers and students generally have to look in places other than the typical CMS-based course to find tools that can facilitate such long-lasting connections. Yet when our students venture outside the confines of the CMS, they sometimes conflict with archaic institutional policies and traditions. When a student at Ryerson University convened a chemistry study group inside Facebook in 2007, the University threatened to expel him for academic misconduct. In his defense, the student observed that he was simply replicating online what was common practice in face-to-face study group and tutorial sessions (Schaffhauser, 2008). The difference between these face-to-face sessions and the groups the student created in Facebook, however, was that the online versions of the study groups would persist over time, perhaps far beyond the students' time at Ryerson. Access to Facebook, unlike access to live study sessions or to the CMS, does not expire when a student graduates. 
While ephemeral access to classmates and course content might have once been adequate, the career ecosystem into which we are sending our students is radically different than it was even just a decade ago. While perhaps a bit stylized, the typical CMS-delivered, contentcentric, lecture-driven course complete with multiple-choice midterm and final exams, does little to prepare students to succeed in a world in which there will always be more new knowledge created every day than they can possibly access, much less assimilate, master, and apply. Given the overwhelming flow of data all around us, our job should be increasingly less focussed on making our students "knowledgeable" and focused instead more on making them "knowledgeable" (Wesch, 2009). By eliminating access to the courses a student participates in within a CMS, an institution not only hampers them during their formal learning careers, but it takes away a potentially invaluable knowledge-able tool for continued success as a lifelong learner. (That is unless, of course, we persist in believing the myth that our students actually master and permanently remember all that they "learn" in our classes.)

Brown and Adler (2008) have argued that the educational status quo is no longer aligned with the realities of the world our students-and frankly, we-live in:

As [they] move from career to career, much of what [they] will need to know will not be what [they] learned in school decades earlier. We are entering a world in which we all will have to acquire new knowledge and skills on an almost continuous basis. (p. 18)

Clarke and Jennings (2009) affirm this assertion: "The new priority is to develop agile minds of resourceful individuals who can locate and master skill sets or the knowledge they need, not simply memorize learning content" (p. 1). The old paradigm of making our students "knowingly prepared" is rapidly losing its value. We should instead help our students be "unknowingly prepared - to be unknowing but to possess the tools and skills to rapidly become 'knowing' at the moment-of-need" (Clarke \& Jennings, 2009, p. 3).

Like much of the educational technology that preceded it, the CMS was designed primarily to support and enhance traditional teaching. It is not coincidental that the first incarnation of Blackboard was branded "CourseInfo." CMSs were born as, and largely remain, easy-to-use (although increasingly complex), course-website-creation tools. As CMSs have evolved and matured, they have connected instructors, students, and content more efficiently than ever before. However, the overwhelming usage patterns of instructors indicate that the CMS has been used primarily to mimic the traditional, semester-based, lecture-driven, content-centric model of instruction - one of bestowing "course info" on students.

If we hope to prepare our students for success during their time at our institutions and in their working lives, we need to equip them with lifelong learning skills. This necessitates a view of learning that is not confined to discrete 14- or 15-week learning periods, loosely bundled together in what we generously call "degree programs." Lifelong learning is a continuous, not a discrete, phenomenon. Unfortunately, the CMS, with its frequent stops and starts, institutionalizes a discrete, disjointed model of learning that mitigates against the cumulative, lifelong, learner-centric experiences we should be providing for and evoking in our students.

\section{Learners as Co-Instructors, Instructors as Co-Learners}

Web 1.0 was about publishing content to the masses. In the mid 1990s, you had to be something of a technology geek to publish a website. Web 2.0 has changed all of that, allowing anyone with a web browser and only modest technical skills to publish blogs, wikis, images, and videos. In a 
Web 2.0 world, the traditional publishers have had to yield to their audience, ceding to them copublishing space, even on their own websites. As such, Dan Gillmor (2006) refers to the online masses today as the "former audience" (p. 136). Increasingly, college students are just as much a part of the "former audience" as are previously passive consumers of popular entertainment and media. No longer do students sit passively in the classroom, restricted only to the authority of the instructor and their textbook for the final word on the subject matter of a lecture. Now they can Google terms, concepts, and events mentioned by the instructor, they txt, Facebook, and Twitter each other about what's being said, and they carry their notes and even the lecture itself out of class with them, recorded on laptops, MP3 recorders, and digital pens to be reviewed and shared.

Jenkins (2006) chronicles a particularly poignant example of a 12-year-old home schooled girl, Heather Lawver, who created an online, fan-authored version of The Daily Prophet, the fictional newspaper in the Harry Potter series (see http://www.dprophet.com). The reporters for Lawver's version of The Prophet were her fellow adolescent students from around the world. At the height of her success running the fictional paper, more than 100 children were regular contributors and "a number of teachers" had incorporated student contributions to the paper into their classroom curriculum (Jenkins, 2006, p.180). Jenkins argues that Lawver's activities, and those of the reporters she recruited, went far beyond a creative outlet for fansparticipants acquired knowledge creation, knowledge pooling, and knowledge sharing skills, gained experiences sharing and comparing value systems, learned how to express and interpret feelings about a literary work, and developed Internet publishing skills (p. 185). Gee (2009) has argued that similarly transferable skills can be acquired in online role-playing games, where players learn to work well with team members, collaborate to solve problems, and hone individual skills in the context while understanding and appreciating others' skills, and so forth.

Most (if not all) of these sorts of activities are absent from the typical CMS-based course. This is true primarily because there is no space provided for students to publish such content and engage in such activities of their own creation. Moreover, students engaged in such activities are unlikely to make the CMS the base of their activities because they would be walled off from the rest of the world, destined for deletion at the end of the semester.

The notion of students actively participating in the processes of capturing, creating, and sharing course content, conversations, and activities turns the centuries-old "sage on the stage" model on its head. However, the CMS paradigm actually works against such a transformation of the relationship between teachers and learners because it privileges the role of the instructor and technically restricts individual students from contributing and to shaping courses in any meaningful way. Sclater (2008) has argued that the term "learning management system" itself suggests "disempowerment-an attempt to manage and control the activities of the student by the university" (p. 2). The tendencies of the CMS are not, he argues, just "minor irritations" but rather forces that "may overtly or subtly align the institutional processes with the software rather than having the system serve the requirements of the institution" (Sclater, 2008, p. 3).

As the scope and scale of the CMS has grown, it has become a core part of almost every institution's enterprise technology infrastructure. This is evidenced perhaps most powerfully by the growth in licensing costs paid to CMS vendors. Between 2000 and 2008, the average licensing cost per campus for commercial CMS skyrocketed 500\% (Delta Initiative, 2009; slide 11). In addition, these figures do not take into account hosting costs that have also grown rapidly with increased CMS adoption and utilization. CMS-related adoption and resourcing decisions, then, are driven by many of the same factors that drive decision-making about other enterprise 
software at colleges and universities. A 2009 report on the state of the LMS in higher education commissioned by the California State System includes a "Holistic View of LMS Decisions" (2009, slide 21). While focused on system-wide CMS implementations, it is nonetheless striking - nay stunning - that this "holistic view" includes such factors as hosting, faculty development, curriculum and instructional course design, multimedia support, and help desk support while making literally no mention of student learning or student activity within the CMS (slide 21).

That students should use technology to be more engaged in their own learning and take greater ownership of it is not a new idea. More than a decade ago, Reeves argued that we should focus on helping students learn with technology rather than from technology (1998). However, it has been precisely the lack of CMS functionality that supports this shift of activity, ownership, and responsibility to students, which has given rise to the idea of a "personal learning environment" or PLE (Educause, 2009). Where once the instructor was the sole (or at lease substantially privileged) possessor of content expertise and certainly the exclusive provider of course materials, learners are now instantaneously able to Google virtually any information about the content of a course (often during the lectures themselves), independently publish their thoughts about it, and interact with others (both inside and outside of the official course roster) about the course and it's subject matter. The additive result of these activities, scattered across the learner's computer and various applications and sites in the cloud, forms a "personal learning environment." For most subjects and most learners, these new affordances facilitate a richer, more meaningful, and longer-lasting learning experience. When students enter the walled garden of the CMS, they are largely "acted upon." Efficacious, self-regulating learners, on the other hand, "act," participating in and taking ownership of their own learning activities—ultimately, what they learn, and how they employ new learning in pursuit of various life projects.

While the feature set of the CMS made it an early Web 2.0-like toolbox for instructors, it has provided relatively few PLE-like affordances to students. The center of gravity in the CMS is decidedly on institutional and instructor efficiency and convenience, not student participation and learning. This should not be surprising given Cuban's (2001) findings that educational technology is used largely to "maintain existing practices" rather than to "revolutionize" or even change in any substantial way, teaching and learning practices. As evidenced by the BYU and Wisconsin usage studies, instructors have largely employed the CMS to automate the past, using it primarily as an instructional e-mail and content delivery system, bringing greater efficiency to old patterns and methods of instruction and course management.

The CMS today is an enterprise, one-size-fits-all teaching toolbox on virtually every college and university campus in the world. While instructors are readily afforded quick and easy access to course site creation tools, working outside the boundaries of the CMS is generally difficult, sometimes expensive, and occasionally discouraged or forbidden by their institutions. While there are economically rational reasons behind decisions to implement (or even impose) a single, vertical teaching and learning technology stack for an entire campus, there are fundamental philosophical and pedagogical problems with this monolithic approach. As Dede (2008) has observed, "the history of tool making shows that the best strategy is to have simultaneously available a variety of specialized tools, rather than a single device that attempts to accomplish everything" (p. 58). In a learning context, he argues that no educational information and communication technology can be "universally good." Rather, he asserts, "the best way to invest in instructional technologies is an instrumental approach that analyzes the 
natures of the curriculum, students, and teachers to select the appropriate tools, applications, media, and environments" (Dede, 2008, p. 59). He concludes with this declaration:

To progress, the field of instructional design must recognize that learning is a human activity quite diverse in its manifestations from person to person, and even from day to day. The emphasis can then shift to developing pedagogical media that provide many alternative ways of teaching, which learners select as they engage in their educational experiences. (Dede, 2008, p. 59)

Sclater (2008) similarly argues that our focus in providing learning technologies should not be on making the most appropriate tools available for learners at various points in the learning process (p. 8).

New, rapidly evolving web technologies are quickly changing the balance of power in the learning environment. In 1999, the authors of The Cluetrain Manifesto declared:

Networked markets are beginning to self-organize faster than the companies that have traditionally served them. Thanks to the web, markets are becoming better informed, smarter, and more demanding of qualities missing from most business organizations. (Levine, Locke, Sears, \& Weinberger, 1999)

Ten years later, it is safe to say that networked learners are beginning to self-organize faster than the schools that have traditionally served them. Thanks to the web, learners are becoming better informed, smarter, and more demanding of qualities missing from most educational institutions.

If "hyperlinks subvert hierarchy" (Levine, et al., 1999), Web 2.0 tools are making the learning space fundamentally and permanently flat. CIOs, academic leaders, and individual faculty members might argue that they need the structure and security of the CMS. We agree that some elements of the CMS should be maintained. However, students, and a growing number of instructors, are engaging in rich, meaningful dialog, content creation, and sharing outside the CMS. Whether we like it or not, the walled garden of the CMS has been breached and the balance of power has shifted. The CMS will soon cease to be the center of our students' learning universe, if it has not already.

\section{Social Learning and the Network Effect}

Brown and Adler (2008) have argued that, "The most profound impact of the Internet, an impact that has yet to be fully realized, is its ability to support and expand the various aspects of social learning" (p. 18). This is in contrast to the prevailing "traditional Cartesian view" of instruction that focuses primarily on the transfer of knowledge-as if it were a substance-from teacher to learner (Brown \& Adler, 2008, p.18). Educational theorists have long argued against the didactic approach. Freire (1970) critiqued what he called "banking education," a model in which student activity is limited to "receiving, filing, and storing the deposits" of information apportioned them by the instructor (p. 72).

We may fruitfully update Freire's metaphor of "banking education" to a metaphor of "downloading learning." So much of what passes for innovative uses of instructional technology today, like the OpenCourseWare collections available from MIT and other universities restricts learners to downloading files. Whether these files are videos, audio podcasts, or text-based PDFs, a unidirectional broadcast of educational media across the network ignores the network's potential for facilitating discourse. Here too the CMS falls short of providing affordances that 
might close the 2-Sigma gap. Content distribution is the predominant modality of "learning" in the CMS. As Wiley et al. (2004) wrote, the paradigm of downloading learning "present[s] learners with one worldview and no opportunity to experience alternatives, hear the stories of others, or ask meaningful questions."

Rather than thinking of educational media as downloadable files that somehow induce learning in the downloader, we prefer to think of educational content as a campfire around which learners gather. A campfire has important nonsocial functions (like providing heat and light) just as educational content has important nonsocial functions (like conveying information); but, the most important function of both the campfire and educational content is the manner in which they draw people together. A good campfire is a thing around which storytelling, singing, and other social interactions happen; a phenomenon Weller (2008) more formally calls a "social object." The same is true for the best educational content-it draws people into arguments, explorations, discussions, and relationships that add depth, meaning, and value to that content.

When combined with tools and environments that afford opportunities for social interaction, educational resources become semiotic tools that influence learners' actions and mediate the learning process. Wertsch (1991) wrote, "Only by being part of action do mediational means come into being and play their role. They have no magical power in and of themselves" (p. 119). One-way reception of content (i.e., downloading) via a CMS is not a meaningful action in Wertsch's sense anymore than purchasing a textbook is. While the increase in access to educational materials provided via the CMS is laudable, access is only a single step in facilitating meaningful learning. Even with significant pedagogical considerations set aside (e.g., the demonstrated usefulness of cooperative learning (Johnson \& Johnson, 1997; Slavin, 1990) or cognitive apprenticeship (Rogoff, 1990), it seems paradoxical that we would we put hundreds, thousands, or millions of learners in front of advanced communications technology so that they can simply retrieve data instead of interacting with each other around that data.

Light's examination of the impact of group study among students at Harvard is particularly compelling. In Making the Most of College, Light (2001) presents the following evidence:

Students who study outside of class in small groups of four to six students, even just once a week, benefit enormously. Group meetings are organized around discussions of the homework, and as a result of their study group discussion, students are far more engaged and better prepared for class, learning significantly more. (p. 52)

The students Light describes were metaphorically gathering around campfires in specific places (like dorm rooms and libraries) at specified times. The Web facilitates these kinds of conversations in ways and on a scale never before possible. Outside the narrow confines of the CMS, large numbers of learners can join in, both synchronously and asynchronously, from around the world, without the artificial constraints of place or time.

Learning is not a simple acquisition activity. A large body of critical analysis and research concur that learning is at least as much a function of social discourse as it is solitary cognition (e.g., Vygotsky, 1962, 1978; or Schon, Brown, et al., 1989). By adopting and deploying CMSs, institutions of higher education are giving short shrift to this reality, to their own detriment and to the detriment of their students. 


\section{The Open Learning Network}

We have argued that the CMS, as currently designed and implemented, is ill-equipped to help teachers and learners close the 2-Sigma gap Bloom identified. We contend that its inadequacy stems from three specific weaknesses of the CMS: (a) the organization of learning experiences into discrete, artificially time-bound units, (b) the predominance of instructor-focused and content-centric tools in the CMS, and (c) the lack of persistent connections between learners, instructors, content, and the broader community across semesters and across class, program, and institutional boundaries.

In light of these shortcomings, we propose the "open learning network" (or OLN) as an alternative to the traditional CMS. While applauding the continued efforts of those in the commercial and open source CMS space to innovate and improve CMS design, implementation and practice, we concur with the Delta Initiative's learning management report-innovative learning technology disruption is more likely to come from outside the current CMS ecosystem than from within (see p. 27). A serious rethinking and reconceptualization of the CMS, its purpose, and function in higher education are unlikely to be forthcoming from Blackboard, Desire2Learn, Moodle, or Sakai. Rather, these disruptions are likely to come from educational technologists and leaders exploring new tools and new approaches to learning. In fact, the Delta Initiative study suggests that there has been no "significant innovation in the core LMS project" since 2004 (see Slide 11), 5 years ago at the time of this writing.

The CMS debate has been largely framed as a choice between the CMS and the PLE. We contend, however, that this is a false dichotomy. Instead of forcing a choice between the two, the OLN we propose is a hybrid between the CMS and the PLE. This means that the OLN is not a single, vertically integrated technology stack. Rather, it consists of a series of modules or standalone applications that perform various discrete functions. By combining several functions into one application, the CMS has forced us to make a trade-off that is suboptimal for learning. Because there is some confidential and proprietary data in the CMS, we have traditionally locked all course data behind a login screen, viewable only by an instructor and the officially enrolled members of his or her class - and then only for the duration of the semester or term. This is perhaps the most debilitating example of CMS technology being used to reinvent the past. The traditional classroom has always been a private, physically, and temporally bounded space. The natural inclination was to replicate that model within the CMS. However, doing so has imposed the limits of the old space in a new space where such limitations do not exist.

This is not to say that everything should be open and publicly viewable in the OLN. We are still bound by legal, moral, and ethical obligations to keep students records and grade related information private and secure. Additionally, some of the content that is published in online courses comes with licensing restrictions that limit viewership to those enrolled at the institution or even in a particular course. Moreover, online quizzes and assessments must be kept private and secure to protect their integrity and to conform to federal distance education requirements.

Accordingly, several key components of the OLN should be private and secure, situated within an institution's intranet. These include student information systems (SISs), identity and role repositories, proprietary content stores, and secure online assessment applications. These are and should remain core components of the institutional IT infrastructure. Beyond these, however, several OLN components need not be private. Faculty and student blogs, wikis, portfolios, and open courseware and open educational resource repositories can be open (at the option and 
discretion of individual faculty members and students). These functions can exist, spread across multiple applications and websites, in the cloud. Some applications might even be mashups of intranet and cloud-based applications.

The OLN model implies a new role for the IT organization. Instead of attempting to provide every application and tool for every purpose, its focus shifts to maintaining the applications and data that are at the core of the institution's business. It then lets faculty members and students use the best applications and tools they can find to do everything else. So that these two seemingly disparate worlds can coexist and be easily navigated by faculty members and students, IT provides bridge applications and functions, such as single sign-on and data harvesting.

A typical OLN might look something like that depicted in Figure 3.

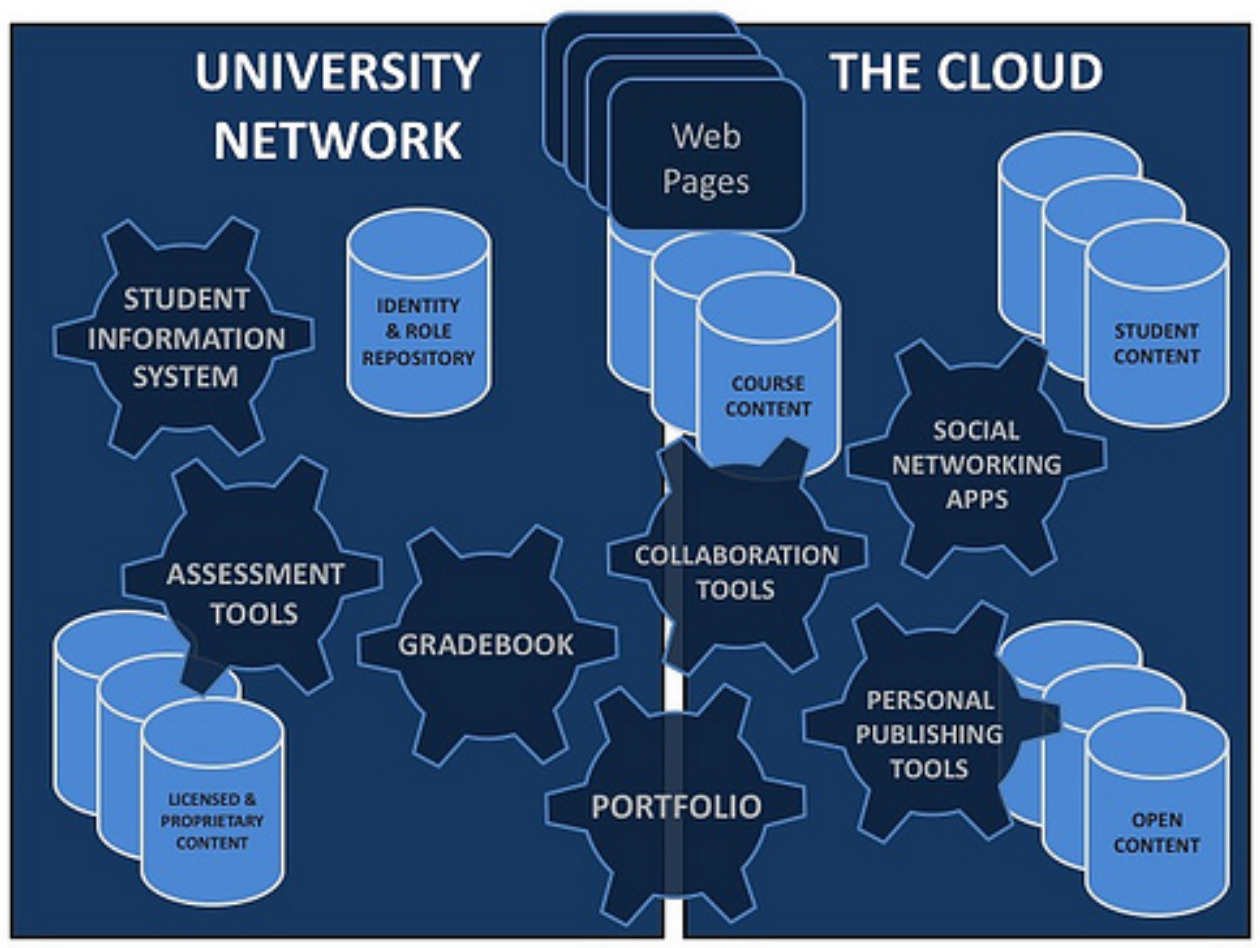

Figure 3. An open learning network.

This model maintains the "core set of functionality" Sclater (2008) suggests should remain within the purview of the institution while facilitating the kind of data exports and imports necessary to allow seamless integration and operation while opening the space necessary for learners to act as co-instructors and for teachers to act as co-learners in a dynamically generated space (p. 9). Siemens (2004) has argued that, "the real issue is that LMS vendors are attempting to position their tools as the center-point for elearning-removing control from the system's endusers: instructors and learners." One of the primary aims of the OLN model is to re-establish teachers and learners at the center of learning activity (both inside and outside of courses).

The OLN also has the significant advantage of being time-persistent. Compared with the frequent starts and stops in the CMS (see Figure 2), much of what happens in the OLN allows learners to build their learning networks over time, since it is not bound to semesters, terms, or 
even the institution. In addition, the artificial boundaries of the CMS are removed thereby allowing the learner to benefit from participation in a broader community of networked learners, further removing the limitations on learner network growth (see Figure 4).

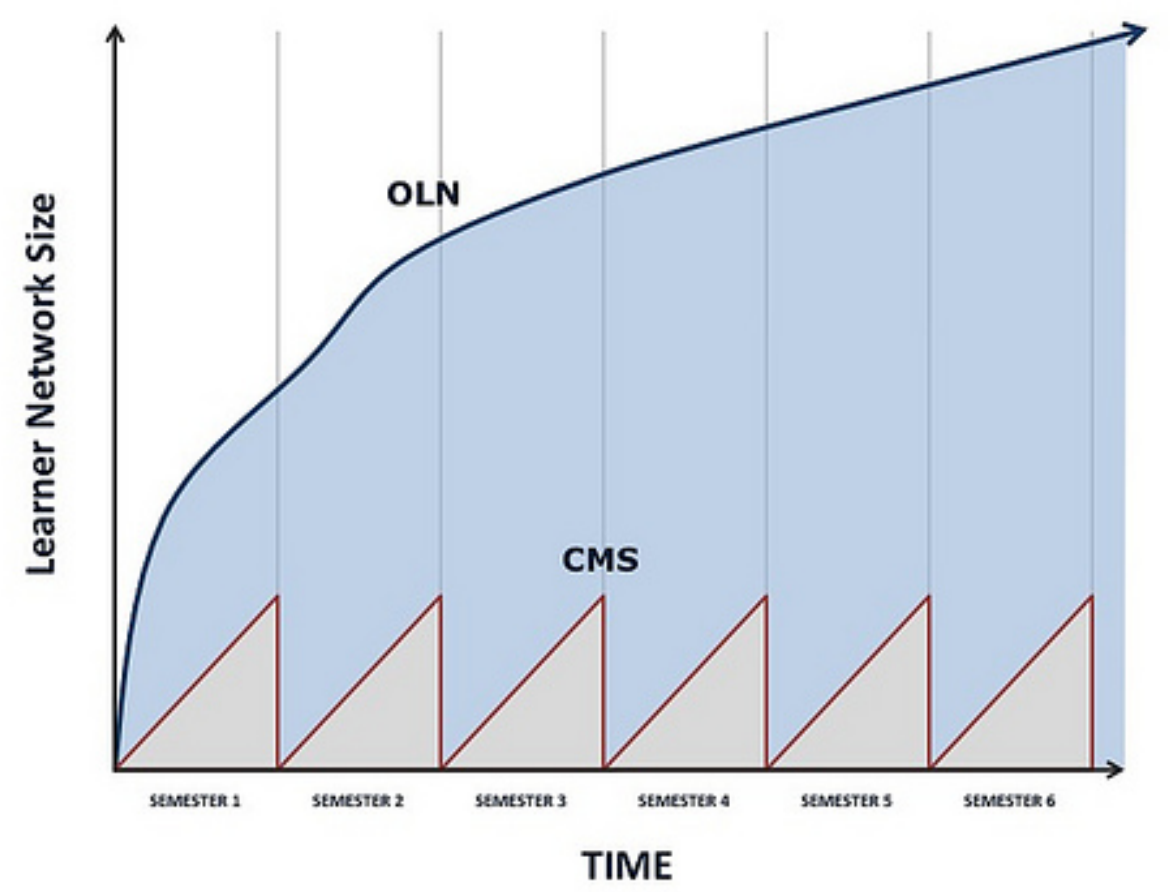

Figure 4. Learner network growth over time: The CMS vs. the OLN.

While this paper is not the appropriate venue for a lengthy technical discussion of the OLN, it is important to note that its viability depends on a robust institutional web services framework, much like that proposed by the e-framework for Education and Research (http://www.e-framework.org). It is also important to note that we do not predict or expect a move from a CMS to an OLN to result in a more stable, reliable learning environment. Nor do we necessarily think that such a move would result in dramatic cost savings. Neither of these factors should be the most influential drivers in a move toward an OLN. Institutions should transition from a CMS to an OLN because doing so is more conducive to accomplishing the short and long-term learning goals they have for their students.

\section{Conclusion}

In this paper, we have argued that features of the CMS and the manner in which it has been implemented have limited the potential impact of the Web on learning. While we do not pretend that the OLN alternative we propose here is sufficient, by itself, to close Bloom's 2-Sigma gap, we maintain that moving away from the CMS toward a more open, flexible, modular, and interoperable learning infrastructure (Bush \& Mott 2009) will help institutions, teachers, and learners more fully benefit from the affordances of the Web. However, it would be naive to suggest that simply changing the underlying technology infrastructure will result in learning improvements of any kind. Indeed, it has been our assertion throughout that any new technology is likely to be used to reinvent the past rather than to create a new future. As White, Ringstaff, and Kelley (2002) note, "Although technology can support change in education, it will have little 
impact without accompanying reform" in the way schools and teachers think about and organize themselves to support learning" (p. 4).

To be clear, our assertions about the weaknesses of the CMS paradigm should also be taken as critiques of the predominant pedagogical model in higher education. Specifically, we believe that institutions and instructors should aim to do more than just transfer knowledge from the professor, the library, and the textbook into their students' brains. And while promising developments are changing the centuries-old stand-and-deliver lecture culture (chief among these being evolving accreditation standards), we recognize that change will not happen all at once simply because we change the technology we use to support teaching and learning. However, as we have argued, the current technological paradigm reinforces and even hinders movement away from this model. The OLN model also has the potential to be used in support of traditional, lecture-based, content-centric courses. This is because it removes artificial time limits, allows for more student autonomy in the learning process, and opens up the learning network thereby removing the barriers that stand in the way of those who are anxious to innovate and employ new learning methodologies.

The place and time-independent nature of the Web affords a plethora of learning activities and learner interactions that are not possible in the place and time-bound classroom. The OLN model is aimed at leveraging these affordances in ways that the CMS does not. For example, discussions that last longer than 50 minutes can be conducted online without prompting or intervention by the instructor. Such discussions can include more voices than those of the students formally enrolled in the class. Whatever connections students make with each other can be maintained via social networking applications of their choosing. Students can capture, annotate, and archive the content they assemble and create in their courses as well as in their less formal learning experiences. In addition, because they are using their tools, they maintain control of and access to the content as long as they choose.

Setting the OLN aside, we believe teachers have a moral obligation to their students to be the best teachers they can be. A significant aspect of being an accomplished teacher means leveraging the best available tools, technologies, and learning environments available in support of specific teaching and learning situations. Given the ever-increasing rate of change and improvement in learning technologies and approaches, committed teachers should be anxious to find and employ new, more effective tools to help their students learn more effectively.

Simply using new technologies is unlikely to improve learning. Although some educational technology evangelists promote the radical idea of "progress for the sake of progress," we eschew this idea. We similarly reject the equally radical Luddite position that ignores technological developments altogether. Rather, in proposing an open learning network that combines the most effective aspects of the CMS with the most desirable aspects of the PLE, we fight to hold a middle position in which teachers thoughtfully leverage the capacities technology provides them in order to best support student learning. We believe that the open learning network is an appropriate middle ground, and is revolutionary primarily in its refusal to be radical in either direction.

More than a quarter century after Bloom threw down the 2-Sigma gauntlet, his challenge remains unmet. While technology has long been thought the best hope for closing the achievement gap, the last decade of mainstream investment in and adoption of educational technology has focused largely on the CMS - a technology that has all but ensured that 
substantial innovation does not occur. The open learning network, on the other hand, is a broadly adoptable platform within which innovation can occur.

One of our faculty colleagues recently reflected that after 30 years of trying to "cover content" he finally realized that he should have been striving to "uncover" it. For the bulk of his career, he has taught large-section classes, the polar opposite of the one-to-one learning arrangements Bloom found to be so effective. While the CMS tends to reinforce the knowledgetransfer model, long deemed the best and only way to teach large groups of students, the OLN poses as an intriguing alternative. Instead of limiting ourselves to knowledge transfer, we can leverage the affordances of the web to uncover content, to help students become more than just temporarily knowledgeable about a subject. We can do so by approximating —and perhaps even surpassing - the efficacy of one-to-one learning relationships. As the tradition-preserving CMS gives way to the OLN and the learning affordances it brings with it, Bloom's challenge may finally be met. 


\section{References}

Ackoff, R. L., \& Greenberg, D. (2008). Turning learning right side up. Upper Saddle River, NJ: Wharton School Publishing.

Anderson, C. (2006). The Long Tail: Why the future of business is selling less of more. New York: Hyperion.

Bloom, B. S. (1984). The 2-sigma problem: The search for methods of group instruction as effective as one-to-one tutoring. Educational Researcher, 13(6), 4-16.

Brown, J. S., \& Adler, R. P. (2008). Minds on fire: Open education, the Long Tail, and Learning 2.0. Educause Quarterly, 42(6), 16-32.

Bush, M., \& Mott, J. (2009). The transformation of learning with technology learner-centricity, content and tool malleability, and network effects. Educational Technology 49(2), 3-20.

Campbell, G. (n.d.). Cognition prints. Retrieved from http://www.gardnercampbell.net/blog1/?page_id=633

Clarke, D. J., \& Jennings, C. (2009). Experiential learning: Bringing knowledge to life. Retrieved from http://toolwire.com/files/ExperientialLearning.pdf

Cuban, L. (2001). Oversold and underused: Computers in the classroom. Cambridge, MA: Harvard University Press.

Dede, C. (2008). Theoretical perspectives influencing the use of information technology in teaching and learning. In J. Voogt and G. Knezek, (Eds.), International handbook of information technology in primary and secondary education. New York: Springer.

Delta Initiative. (2009). The state of learning management in higher education systems. Retrieved from https://deltainitiative.webex.com/deltainitiative/ldr.php?AT=pb\&SP=MC\&rI....

Educause. (2009). 7 things you should know about...personal learning environments. Educause Learning Initiative. Retrieved from http://net.educause.edu/ir/library/pdf/ELI7049.pdf.

Freire, P. (1970). Translated by Ramos, B. A. (2000). Pedagogy of the oppressed: 30th anniversary edition. London: Continuum.

Friedman, T. L. (2005). The world is flat: A brief history of the twenty-first century. New York: Farrar, Straus and Giroux.

Gee, J. P., (2009). The gamer's edge. Retrieved from http://www.pbs.org/wgbh/pages/frontline/digitalnation/virtual-worlds/vid...

Gillmor, D. (2006). We the media: Grassroots journalism by the people, for the people. Sebastopol, CA: O'Reilly.

Herrington, J., Reeves, T., \& Oliver, R. (2005). Online learning as information delivery: Digital myopia. Journal of Interactive Learning Research, 16(4): 353-67.

Jenkins, H. (2006). Convergence culture: Where old and new media collide. New York: NYU Press.

Johnson, D. W., \& Johnson, R. T. (1997). Joining together: Group theory and group skills (6th ed.). Boston: Allyn \& Bacon. 
Levine, R., Locke, C., Sears, D., \& Weinberger, D. (1999). The cluetrain manifesto. http://www.cluetrain.com.

Light, R. L. (2001). Making the most of college: Students speak their minds. Cambridge, MA: Harvard University Press.

Milligan, C. (2006). The road to the personal learning environment? CETIS. Retrieved from http://zope.cetis.ac.uk/members/ple/resources/colinmilligan.pdf.

Morgan, G. (2003). Faculty use of course management systems. ECAR. Retrieved from http://net.educause.edu/ir/library/pdf/ers0302/rs/ers0302w.pdf.

Nagel, D. (2008). Education IT spending, fueled by Telecom, to top \$56 billion by 2012. Campus Technology, 18 September. Retrieved from http://www.campustechnology.com/Articles/2008/09/Education-IT-Spending-F....

Reeves, T. (1998). The impact of media and technology in schools: A research report prepared for The Bertelsmann Foundation. Retrieved from http://www.athensacademy.org/instruct/

Reeves, T. (2006). Changing how we evaluate the impact of computers in education in a flat world. Retrieved from http://it.coe.uga.edu/ treeves/GCCCE2006KeynoteReeves.ppt (Beijing, China, 2006).

Reeves, T.C. (1998). The impact of media and technology in schools: A research report prepared for The Bertelsmann Foundation. Retrieved from http://www.athensacademy.org/instruct/media_tech/reeves0.html

Reigeluth, C. M. (1999). What is instructional design theory and how is it changing? In C. M. Reigeluth (Ed.), Instructional design theories and models: A new paradigm of instructional theory (pp. 5-29). Hillsdale, NJ: Lawrence Erlbaum Associates.

Rogoff, B. (1990). Apprenticeship in thinking: Cognitive development in social context. New York: Oxford University Press.

Schaffhauser, D. (2008). Student faces expulsion over Facebook study group. Campus Technology. Retrieved from http://campustechnology.com/Articles/2008/03/Student-FacesExpulsion-ove...).

Sclater, N. (2008). Web 2.0, Personal learning environments, and the future of learning management systems. ECAR, Volume 2008, Issue 13.

Shirky, C. (2008). Here comes everybody. New York: Penguin.

Siemens, G. (2004). Learning Management Systems: The wrong place to start learning. elearnspace. 22 November. Retrieved from http://www.elearnspace.org/Articles/lms.htm.

Slavin, R. E. (1990). Research on cooperative learning: Consensus and controversy. Educational Leadership, 47(4).

University of North Carolina. (2009). Sakai pilot evaluation final report. October 15, 2009. Retrieved from http://www.unc.edu/sakaipilot/evaluation/FinalRept-Oct15-09-sm.pdf.

Vygotsky, L. S. (1962). Thought and language. Cambridge MA: MIT Press.

Vygotsky, L.S. (1978). Mind in society. Cambridge, MA: Harvard University Press. 
Webb, L. (2009). The future of higher education: Two contrasting viewpoints. UtahPolicy.com. Retrieved from http://www.utahpolicy.com/featured_article/the-future-higher-education-t...

Weller, M. (2008). Social objects in education. Retrieved from http://nogoodreason.typepad.co.uk/no_good_reason/2008/01/whats-a-social....

Wesch, M. (2009). From knowledgable to knowledge-able: Learning in new media environments. Retrieved from http://www.academiccommons.org/commons/essay/knowledgable-knowledge-able

White, N., Ringstaff, C, \& Kelley, L. (2002). Getting the most from technology in schools. Retrieved from http://www.wested.org/online_pubs/kn-02-01.pdf.

Wiley, D., Padron, S., Lambert, B., Dawson, D., Nelson, L., Barclay, M., \& Wade, D. (2004). Overcoming the limitations of learning objects. Journal of Educational Multimedia and Hypermedia, 13(4), 507-521. 